\title{
pesquisa
}

ARAUJO, J.S.P.; GONÇALVES, K.S.; OLIVEIRA, B.C.; RIBEIRO, R.L.D.; POLIDORO, J.C. Efeito do acibenzolar-S-methyl sobre murcha-bacteriana do tomateiro. Horticultura Brasileira, Brasília, v.23, n.1, p.05-08, jan.-mar. 2005.

\section{Efeito do acibenzolar-S-methyl sobre murcha-bacteriana do tomateiro}

\author{
João Sebastião de P. Araujo ${ }^{1}$; Karin da S. Gonçalves ${ }^{2,3}$; Bruno C. de Oliveira ${ }^{2,4}$; Raul de L.D. Ribeiro'; \\ José Carlos Polidoro ${ }^{1,5}$ \\ ${ }^{1}$ UFRRJ, Depto. Fitotecnia, BR 465, Km 7, 23851-970 Seropédica-RJ;.E-mail: araujoft@ufrrj.br; ${ }^{2}$ Graduando Engenharia Agronômica; \\ ${ }^{3}$ Bolsista Sinteeg/UFRRJ; ${ }^{4}$ Bolsista Pibic/CNPq; ${ }^{5}$ Bolsista ProDoc/CAPES
}

\section{RESUMO}

Avaliou-se a ação ativadora do acibenzolar-S-methyl (aSm) na indução de resistência à murcha-bacteriana do tomateiro, causada por Ralstonia solanacearum. Plantas das cultivares Santa Clara, Diana e AF-2573, receberam sete aplicações semanais do aSm (2,5 g i.a./100 L água), via pulverização foliar ou rega, iniciando-se 14 dias após a semeadura. Com 32 dias de idade, as mudas foram transplantadas para solo infestado com $R$. solanacearum, onde receberam outras quatro aplicações semanais do ativador, enquanto no tratamento-controle aplicou-se apenas água. Através de avaliações diárias do número de folhas e plantas murchas calcularam-se os valores da área abaixo da curva de progresso da doença. Sintomas de murcha evoluíram mais vagarosamente nas três cultivares quando as plantas foram pulverizadas com o aSm. Esse efeito foi significativo até a quarta semana do transplantio para solo infestado $\operatorname{com} R$. solanacearum.

Palavras-chave: Ralstonia solanacearum, Lycopersicon esculentum, resistência sistêmica adquirida.

\begin{abstract}
Effect of acibenzolar-S-methyl on tomato bacterial wilt

The potential of acibenzolar-S-methyl (aSm) as a plant resistance activator was evaluated against tomato bacterial wilt caused by Ralstonia solanacearum. Plants of the cvs. Santa Clara, Diana and AF-2573 received seven weekly applications of aSm (2.5 g i.a./100 $\mathrm{L}$ water), by foliar sprays or soil drenches. The first application was carried out 14 days after sowing. 32-day old plantlets were transplanted into infested soil with $R$. solanacearum where they received four weekly applications of the activator. Control plots received only water. Disease severity was evaluated daily through the number of wilted leaves and plants. With the obtained data we estimated the area under the disease progress curve. Wilt symptoms increased at a slower rate in the three cvs. when aSm was sprayed. This effect was significant up to four weeks after transplanting in infested soil with $R$. solanacearum.
\end{abstract}

Keywords: Ralstonia solanacearum, Lycopersicon esculentum; systemic acquired resistance.

\section{(Recebido para publicação em 1 de dezembro de 2003 e aceito em 5 de novembro de 2004)}

$\mathrm{N}$ a cultura do tomateiro (Lycopersicon esculentum Mill.), a murcha-bacteriana (MB), causada por Ralstonia solanacearum E.F. Smith (Yabuuchi et al., 1995), é uma das doenças de maior importância, ocorrendo em grande parte das regiões tropicais e subtropicais (Martin et al., 1982), notadamente quando a temperatura do ar ultrapassa $25^{\circ} \mathrm{C}$ (Lopes e QuezadoSoares, 1997). A bactéria infecta as raízes, movendo-se sistemicamente ao longo do xilema e ocasionando sintomas de murcha. A doença ocorre praticamente em quase todo o território nacional, limitando o cultivo do tomateiro em regiões mais quentes, incluindo áreas de produção do Norte, Nordeste, Centro-Oeste e Sudeste brasileiro.

Os estudos sobre a patogenicidade da bactéria e sua variabilidade genética, ainda que incompletos, fornecem informações sobre a composição das populações prevalentes nas diversas áreas agrícolas. Nesse sentido, a identificação de biovares, serovares ou patotipos, e sua respectiva distribuição geográfica, é altamente desejável, especialmente para melhor compreensão da ecologia do patógeno e de questões de natureza etiológica, bem como para orientar o controle e a incorporação de resistência em cultivares. Considerando o círculo de hospedeiros da bactéria, a raça 1 afeta um maior número de solanáceas cultivadas (tomateiro, batatinha, berinjela, jiló, fumo), incluindo as biovares I, III e IV. A raça 2 da bactéria afeta bananeira e helicônias, enquanto a raça 3 (biovar II) é considerada específica de batatinha, ocorrendo em regiões mais frias, embora possa naturalmente infectar outras solanáceas. Sua ampla gama de hospedeiros, alta variabilidade genética e a sua sobrevivência no solo por longos períodos são fatores responsáveis pelo insucesso de antibióticos, fungicidas, fertilizantes e programas de melhoramento genético avaliados para controle da murcha-bacteriana (Hartman e Elphinstone, 1994).
A resistência de plantas a patógenos baseia-se, em grande parte, na multiplicidade de barreiras e mecanismos de defesa já existentes e que independem da chegada do inóculo ao sítio de infeção. Essas defesas são genericamente denominadas de constitutivas, inespecíficas ou estáticas. As plantas superiores possuem, ainda, outros mecanismos de defesa, supostamente mais eficientes, os quais aparentemente, permanecem inativos ou latentes, somente sendo acionados após serem elas expostas a agentes ativadores (abióticos ou bióticos). Nestes casos, a resistência é dita dinâmica, pósinfeccional ou induzida (Agrios, 1997).

A indução da resistência de plantas a patógenos é conhecida de longa data (Chester, 1933; Muller e Borger, 1940). Entretanto, apenas mais recentemente o potencial do seu emprego no controle de fitomoléstias tem recebido a merecida atenção (Gorlach et al., 1996; Kloepper et al., 1997; Oostendorp et al., 2001). 
Dentre as substâncias indutoras de resistência, o ácido salicílico e seus análogos são dos mais importantes. O ácido salicílico (AS) representa o primeiro composto derivado de plantas demonstrado como indutor de resistência sistêmica adquirida (SAR). Posteriormente, um análogo do AS, o ácido 2,6 dicloroisonicotínico (INA), foi o primeiro composto sintético a ativar a SAR. Entretanto, tanto o AS como o INA são fitotóxicos para a maioria das plantas cultivadas e, em conseqüência, não têm potencial para uso comercial como protetores. Mais recentemente, outro análogo do AS, o acibenzolar-S-methyl (éster S-metil do ácido benzo-1,2,3tiadiazole-7 carbotióico), um composto do grupo benzotiadiazole, revelou-se um potente ativador de SAR, conferindo proteção em condições de campo contra um amplo espectro de patógenos de diversas espécies de plantas cultivadas (Gorlach et al., 1996). Acredita-se que o acibenzolar-S-methyl (aSm) ative mecanismos de defesa representados por barreiras bioquímicas e estruturais em plantas geneticamente suscetíveis (Gorlach et al., 1996; Oliveira et al., 1997; Latunde-Data e Lucas, 2001; Louws et al., 2001).

No presente estudo, buscou-se detectar possíveis efeitos da aplicação do aSm sobre a severidade dos sintomas em tomateiro da murcha-bacteriana incitada por R. solanacearum.

\section{MATERIAL E MÉTODOS}

A pesquisa foi desenvolvida na Universidade Federal Rural do Rio de Janeiro, Seropédica, (RJ), durante o verão de 2001/2002, época favorável ao desenvolvimento da doença. Sementes das cvs. de tomateiro Santa Clara I-5300, Diana e AF-2573 foram germinadas em bandejas de poliestireno expandido de 128 células, previamente esterilizadas com solução a $0,5 \%$ de hipoclorito de sódio e abastecidas com substrato comercial (Eucatex Mineral Ltda.). Utilizou-se uma única semente por célula. Em seguida, as bandejas permaneceram em câmara de germinação $\left(23-25^{\circ} \mathrm{C} \mathrm{e} 90 \% \mathrm{UR}\right)$ por sete dias, sendo então transferidas para casade-vegetação $\left(22-28^{\circ} \mathrm{C}\right)$, onde receberam irrigações diárias.
Os tratamentos iniciaram-se 14 dias após o plantio, consistindo da aplicação semanal do aSm na concentração de 2,5 g i.a./100 L água (conforme recomendação do fabricante), nos modos de pulverização sobre a área foliar ou da rega de 5,0 $\mathrm{ml}$ da suspensão junto ao colo das mudas. Tomateiros das três cultivares utilizadas no estudo foram também pulverizados somente com água para servir como controle. Ainda nas bandejas, sob condições de casa-de-vegetação, foram efetuadas outras aplicações do aSm, aos 21 e 28 dias.

Com a idade de 32 dias, as mudas foram transplantadas das bandejas para área do infectário de $R$. solanacearum, estabelecido pela PESAGRO-RIO (EE Seropédica), onde receberam outras quatro aplicações semanais do aSm, resultando no total de sete aplicações. $\mathrm{O}$ infectário é constituído de canteiros medindo 2 × $5 \mathrm{~m}$, contornados em todas as dimensões por paredes de alvenaria e contendo solo artificialmente infestado com R. solanacearum (Araujo, 1995; Moura, 1996). O nível populacional da fitobactéria nos canteiros foi periodicamente avaliado e mantido por meio de plantios sucessivos com cultivares suscetíveis de tomateiro. A avaliação preliminar no verão 2000/2001 revelou $100 \%$ de plantas murchas.

Os tratamentos foram distribuídos no esquema de parcelas subdivididas, onde os níveis de aplicação (1- aSm via pulverização; 2- aSm via rega e 3-água) foram distribuídos na parcela e as cultivares na subparcela. O delineamento experimental utilizado foi de blocos casualizados, com nove repetições. Cada unidade experimental, por sua vez, continha três plantas, em espaçamento de 0,5 x 0,6 m. Durante o ensaio, foram feitas irrigações diárias com volume uniforme de água, por meio de mangueira e adubações de cobertura com uréia e esterco de galinha curtido.

As avaliações iniciaram-se quatro dias após o transplantio das mudas para o infectário, sendo realizadas a cada três ou quatro dias. Para tanto, contabilizouse o número de folhas dos tomateiros, bem como o número de plantas e folhas com sintomas de murcha, em horários de temperaturas mais elevadas. Cobrin- do um período de 67 dias, foram considerados dados de sete avaliações. Os valores percentuais de folhas e de plantas sintomáticas foram utilizados para cálculo da área abaixo da curva de progresso da doença (AACPD). Os dados relativos à AACPD foram então submetidos à análise de variância, após transformação para função raiz quadrada. Empregou-se o teste de Scott-Knott para comparação de médias, em nível de 5\% de significância.

Todas as plantas que apresentaram murcha irreversível foram levadas ao laboratório e submetidas a testes de exsudação bacteriana ao microscópio ótico e isolamentos em meio de cloreto de tetrazólio-TZC (Kelman, 1954), a fim de confirmar a infeção dos tomateiros por $R$. solanacearum.

\section{RESULTADOS E DISCUSSÃO}

Efeitos dos tratamentos com aSm na redução da severidade da murcha-bacteriana foram observados nas três cultivares de tomateiro. Não ocorreram diferenças significativas entre cultivares, nem efeito da interação cultivar $x$ tratamento. A aplicação do aSm promoveu redução significativa do progresso da doença. O tratamento via pulverização destacou-se quanto a essa redução, estimada pelo percentual de folhas murchas, embora não tenha diferido estatisticamente do tratamento de rega (Tabela 1).

Indicativos de indução de resistência ou de proteção nos três genótipos (Santa Clara, Diana e AF-2573) surgiram 12 dias após o transplantio, com maior severidade inicial da murcha-bacteriana em plantas das parcelas não-tratadas. Aos 21 dias aproximadamente, $55 \%$ das plantas testemunhas apresentavam sintomas da doença. Nessa ocasião, os tratamentos com aSm em pulverização ou rega, apresentavam 31\% e $35 \%$ de plantas murchas, respectivamente (Figura 1). Aos 31 dias, o tratamento referente à aplicação do aSm via pulverização revelava, ainda, significativa diminuição do número de plantas murchas, situando-se em 50\%, contra $69 \%$ e $73 \%$ nas parcelas tratadas com aSm via rega e água, respectivamente. A partir de 58 dias, com o progresso da doença, os valores aproximaram-se, mas 
se mantiveram distintos do controle, onde todas as plantas já haviam sucumbido. Considerando a severidade da doença, medida por meio do número de folhas murchas, efeito significativo foi detectado somente para o tratamento em que o aSm foi aplicado por pulverização (Figura 2). Dessa forma, tomateiros ativados com o aSm em pulverização desenvolveram menos sintomas da murcha ao longo de todo o período do experimento, consequentemente resultando em atraso no desenvolvimento da doença e redução de sua severidade, comparados aos controles. Fato semelhante foi observado por Silva et al. (2000), em casa-de-vegetação, ao avaliarem o efeito do aSm na indução de resistência em tomateiro a Xanthomonas campestris pv. vesicatoria (Doidge) Dye.

A redução da severidade da murcha pelo aSm observada na presente investigação pode ser decorrente de indução de resistência, quando do produto aplicado na parte aérea do tomateiro. Tal hipótese tem sido também considerada, função de experimentos realizados com diferentes patossistemas (Latunde-Data e Lucas, 2001; Louws et al., 2001; Cools e Ishii, 2002; Smith-Becker et al., 2003).

Poucos estudos foram divulgados com referência à ativação de resistência sistêmica pelo aSm e sua eficácia no controle de bactérias fitopatogênicas. Devem ser registrados os resultados obtidos por Romero et al. (2001), indicando que o aSm é capaz de induzir resistência a Xanthomonas axonopodis pv. vesicatoria (Vauterin) incitante da mancha bacteriana do pimentão. Essa resistência foi expressa três dias após a pulverização com aSm e prolongou-se por duas semanas. Castro et al. (1999), por sua vez, verificaram proteção do tomateiro contra Pseudomonas syringae pv. tomato (Okabe) Young, Dye e Wilkie, agente causal da pinta bacteriana, empregando igual dosagem do aSm (2,5 g i.a/100 L água). Analogamente, Fidantsef et al. (1999) demonstraram reduções significativas na severidade dessa última doença desde que aplicado o aSm seis dias antes da inoculação com a bactéria.

Louws et al. (2001) detectaram efeito positivo do aSm no controle das
Tabela 1. Severidade da murcha-bacteriana expressa pela área abaixo da curva de progresso da doença, em plantas de tomateiro tratadas com acibenzolar-S-methyl (aSm a 2,5 g i.a./100 L água), via pulverização foliar ou rega, crescendo em solo infestado com Ralstonia solanacearum. Seropédica (RJ), UFRRJ, 2001/2002.

\begin{tabular}{lcc}
\hline Tratamento & \multicolumn{1}{c}{ Média } & Comparação \\
\hline Controle * $^{*}$ & $3713,569^{* *}$ & $\mathrm{~B}$ \\
Rega & 3435,691 & $\mathrm{~A}$ \\
Pulverização & 2941,176 & $\mathrm{~A}$ \\
\hline
\end{tabular}

*Controle $=$ plantas tratadas com água isenta de aSm $;{ }^{* *}$ valores representam médias de nove repetições; médias seguidas da mesma letra não diferem pelo teste de Scott-Knott a $5 \%$ de significância.

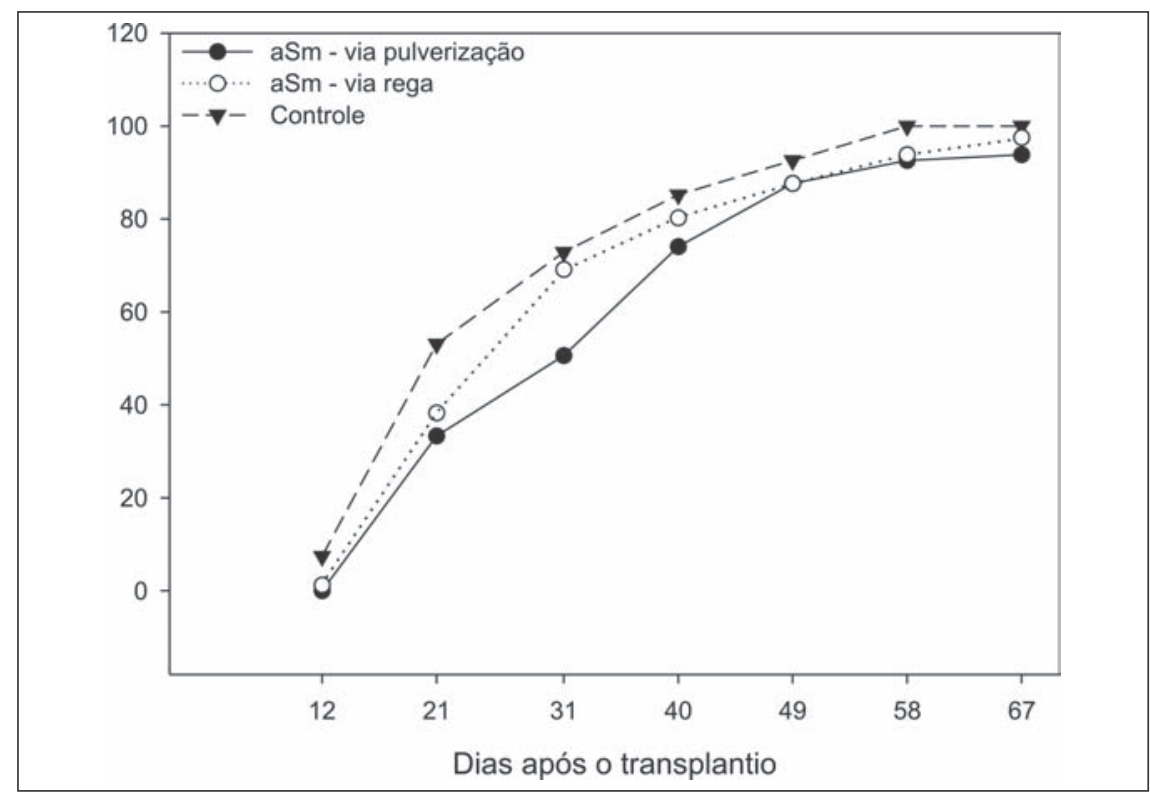

Figura 1. Percentual de plantas de tomateiro com sintomas da murcha-bacteriana, tratadas com acibenzolar-S-methyl (aSm a 2,5 g i.a./100 L água), aplicado em pulverização foliar ou rega, crescendo em solo infestado com Ralstonia solanacearum. Seropédica (RJ), UFRRJ, 2001/2002.

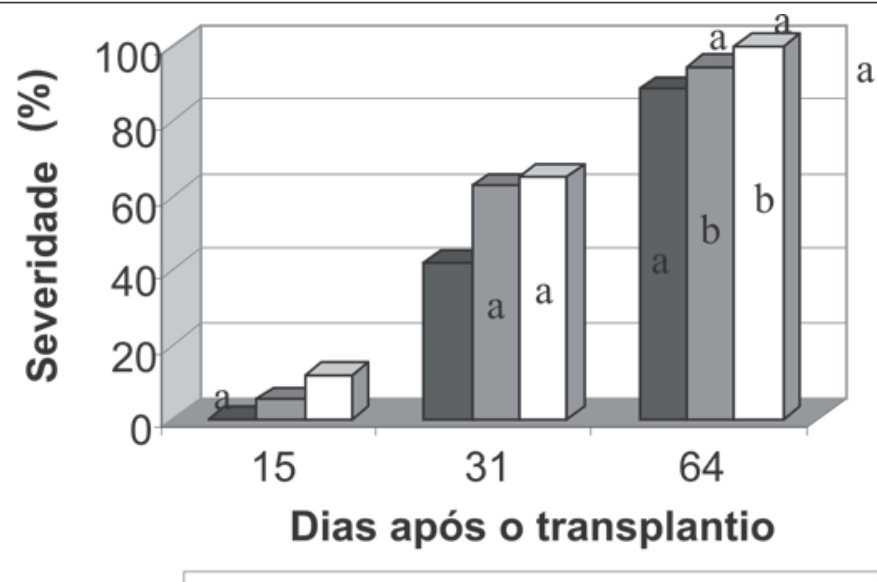

- Pulverização $\square$ Rega $\square$ Controle

Figura 2. Severidade da murcha bacteriana em tomateiro tratado com acibenzolar-S-methyl (aSm a 2,5 g i.a./100 L água), aplicado em pulverização foliar ou rega, e crescendo em solo infestado com Ralstonia solanacearum. Colunas marcadas com a mesma letra representam valores médios que não diferem pelo teste de Scott-Knott a 5\% de significância. Seropédica (RJ), UFRRJ, 2001/2002. 
bacterioses do tomateiro causadas por Xanthomonas vesicatoria (Vauterin) e por Pseudomonas syringae pv. tomato, em ensaios de campo. O produto proporcionou controle igual ou superior ao de compostos cúpricos. $\mathrm{O}$ peso seco e o crescimento de mudas na fase de transplantio foram, contudo, negativamente afetados. Os autores concluíram que o emprego de ativadores de resistência, em plantas sob condições de estresse, pode envolver fatores constitutivos de regulação de crescimento, resultando em fitotoxicidade.

Em concordância com o que relataram Silva et al. (2000), no presente estudo não foi detectado qualquer efeito fitotóxico em tomateiro, com as sete aplicações do aSm.

$\mathrm{O}$ uso de cultivares resistentes de tomateiro tem sido considerado como o método mais efetivo para o controle da murcha-bacteriana. Já foram identificadas várias fontes de resistência, as quais têm sido incluídas em programas de melhoramento genético do tomateiro em todo o mundo (Hartman e Elphinstone, 1994). Contudo, existem evidências indicando que a resistência ao agente da murcha bacteriana não é estável, considerando-se diferentes localidades (Hanson et al., 1996). Nesse contexto, a indução de resistência sistêmica torna-se bastante interessante, como componente de um manejo integrado, somando-se, por exemplo, ao emprego de cultivares menos suscetíveis ou tolerantes a $R$. solanacearum.

Segundo alguns autores (Oostendorp et al., 2001; Louws et al., 2001), o aSm apresenta as vantagens de ser um produto economicamente viável, com doses de recomendação muito baixas, perfil ecotoxicológico aceitável, amplo espectro de ação, com base em mecanismo que não apresenta risco maior de seleção de estirpes resistentes de fitopatógenos.

Embora não se disponha de dados experimentais em condições de campo, os resultados presentemente obtidos indicaram o potencial do aSm, uma vez que o ensaio foi conduzido em solo altamente infestado com $R$. solanacearum, onde muito dificilmente há escape, e realizado sob condições de ambiente super favoráveis à incidên- cia da doença. Acredita-se que em áreas de cultivo comercial de tomateiro os níveis populacionais da bactéria não sejam comparáveis àqueles existentes no infectário ora utilizado.

\section{AGRADECIMENTOS}

À PESAGRO-RIO (EE Seropédica), na pessoa da Dra ${ }^{\mathrm{a}}$. Maria do Carmo de A. Fernandes, por disponibilizar o infectário de $R$. solanacearum; à Syngenta Proteção de Cultivos Ltda., pela doação do produto; e à Prof ${ }^{a}$. Margarida Goréte F. do Carmo (Dept ${ }^{\circ}$. Fitotecnia/IA - UFRRJ), pela colaboração no manuscrito original.

\section{LITERATURA CITADA}

AGRIOS, G.N. Plant Pathology. 4 ed. San Diego: Academic Press, 1997. 635 p.

ARAUJO, J.S.P. Produção de bacteriocinas por estirpes brasileiras de Pseudomonas solanacearum E.F. SMITH e perspectivas de sua utilização no controle biológico da murcha bacteriana. 1995. 69 F. (Tese Mestrado) - UFRRJ, Seropédica.

CASTRO, R.M.; AIZAWA, J.; GARCIA, L.D. Protection on tomatoes against bacterial speck and tomato canker after CGA 245.704 application. BRF243 98ª.doc, São Paulo: Novartis Bioscience in house tests proceedings. 1999. 8 p. CHESTER, K.S. The problem of acquired physiological immunity in plants. Q. Rev. Biol., v.8, p.275-324, 1933.

COOLS, H.J.; ISHII, H. Pre-treatment of cucumber plants with acibenzolar-S-methyl systemically primes a phenylalanine ammonia lyase gene (PAL1) for enhanced expression upon attack with a pathogenic fungus. Physiological and Molecular Plant Pathology, v.61, n.5, p.273-280, 2002.

FIDANTSEF, A.L.; STOUT, M.J., THALER, J.S.; DUFFEY, S.S.; BOSTOCK, R.M. Signal interactions in pathogen and insect attack: expression of lipoxygenase, proteinase inhibitor II, and pathogenesis-related P4 in the tomato, Lycopersicon esculentum. Physiological and Molecular Plant Pathology, v.54, p.97-114, 1999. GORLACH, J.; VOLRATH, S.; KNAUFBEITER, G.; HENGY, G.; BECKHOVE, U.; KOGEL, K.H.; OOSTENDORP, M.; STAUB, T.; WARD, E.; KESSMANN, H.; RYALS, J. Benzothiadiazole, a novel class of inducers of systemic resistance, activates gene expression and disease resistance in wheat. The Plant Cell, v.8, p.629-643, 1996.

HANSON, P.M.; WANG, J.F; LICARDO, O.; HANUDIN, MAH SY; HARTMAN G.L.; LIN, Y.C.; CHEN,T.J. Variable reaction of tomato lines to bacterial wilt evaluated at several locations in Southeast Asia. Hortscience, v.31, n.1, p.143-146, 1996.

HARTMAN, G.L.; ELPHINSTONE, J.G. Advances in the control of Pseudomonas solanacearum race 1 in major food crops. In: HAYWARD, A.C.; HARTMAN, G.L. Bacterial wilt: the disease and causative agent, Pseudomonas solanacearum. CAB International. 1994, p.157-177.
KELMAN, A. The relationship of pathogenicity in Ralstonia solanacearum to colony appearance on a tetrazolium medium. Phytopathology, v.44, p.693. 1954.

KLOEPPER, J.W; TUZUN, S.; ZEHNDER, G.W.; WEI, G. Multiple disease protection by rhizobacteria that induce systemic resistance historical precedence. Phytopathology, v.87, p.136-173, 1997.

LATUNDE-DADA, A.O.; LUCAS, J.A. The plant defense activator acibenzolar-S-methyl primes cowpea (Vigna unguiculata (L.) Walp.) seedlings for rapid induction of resistance. Physiology Molecular Plant, v.58, n.5, p.199-208, 2001.

LOPES, C.A.; QUEZADO-SOARES, A.M. Doenças Bacterianas das Hortaliças. Diagnose e controle. Embrapa SPI. Brasília,1997. 70 p.

LOUWS, F.J.; WILSON, M.; CAMPBELL H.L. Field control of bacterial spot and bacterial speck of tomato using a plant activator. Plant Disease, v.85, n.5, p.481-488, 2001.

MARTIN, C.; FRENCH, E.R.; NYDEGGER, U. Strains of Pseudomonas solanacearum affecting solanaceae in the Americas. Plant Disease, v.66, p.458-460, 1982.

MOURA, A.B. Actinomicetos como agentes potenciais de controle biológico da murcha bacteriana (Pseudomonas solanacearum) e como promotores de crescimento de tomateiro. 1996. 132 F. (Tese Doutorado) - UFV, Viçosa.

MULLER, K.O.; BORGER, H. Experimentelle Untersuchugen uber die Phytophthora-Resistenz der Kartoffel. Arbiten der Biologischen Reichsanstalt, Land-und Forstwirtschaft, v.23, p.189-231, 1940.

OLIVEIRA, R.F.; PASCHOLATI, S.F.; LEITE, B. Papilla formation and peroxidase activity in Mimosa scabrella hypocotyls inoculated with the non-pathogen Colletotrichum graminicola. Fitopatologia Brasileira, Brasília, v.22, p.195197, 1997.

OOSTENDORP, M.; KUNZ, W.; DIETRICH, B.; STAUB, T. Induced disease resistance in plants by chemicals. European Journal of Plant Pathology, v.107, n.1, p.19-28, 2001.

ROMERO, A.M.; KOUSIK, C.S.; RITCHIE, D.F. Resistance to bacterial spot in bell pepper induced by acibenzolar-S-methyl. Plant Disease, v.85, p.189-194, 2001.

SILVA, L.H.C.P.; RESENDE, M.L.V.; MAGALHÃES JÚNIOR, H.; CAMPOS, J.R.; CASTRO, R.M.; CASTRO, A.M.S. Épocas e modo de aplicação do ativador de plantas benzothiadizole (BTH) na proteção contra a mancha bacteriana em tomateiro. Horticultura Brasileira, Brasília, v.8, p.375-376, 2000 (Suplemento).

SMITH-BECKER, J.; KEEN, N.T.; BECKER, J.O. Acibenzolar-S-methyl induces resistance to Colletotrichum lagenarium and cucumber mosaic virus in cantaloupe. Crop Protection, v.22, n.5, p.769-774, 2003.

YABUUCHI, E.; KOSAKO, Y.; YANO, I.; HOTTA, H.; NISHIUCHI, Y. Transfer of two Burkholderia and an Alcaligenes species to Ralstonia gen. nov.: proposal of Ralstonia pickettii (Ralston, Palleroni and Doudoroff, 1973) com. nov., Ralstonia solanacearum (Smith 1986) comb. nov. and Ralstonia eutropha (Davis, 1969) comb. nov. Microbiological Immunology. v.39, p.897904, 1995. 